\title{
The nutrition transition in Cuba in the nineties: an overview
}

\author{
Arturo Rodríguez-Ojea ${ }^{1, *}$, Santa Jiménez ${ }^{2}$, Antonio Berdasco ${ }^{3}$ and Mercedes Esquivel ${ }^{3}$ \\ 'Department of Nutrition, Faculty of Medical Science 'Calixto Garcia', c/o lleana Alfonso, Institute of Nutrition and \\ Food Hygiene, Infanta 1 158, CP 10300 Havana, Cuba: ${ }^{2}$ Institute of Nutrition and Food Hygiene, Havana, Cuba: \\ ${ }^{3}$ Department of Growth and Development, Faculty of Medical Science 'Julio Trigo', University of Havana, Havana, \\ Cuba
}

\begin{abstract}
Objective: To describe and analyse the changes in diet, physical activity and body composition of the Cuban population during the 1990s and the health implications of these changes.

Design and setting: Data on national food balance and physical activity are from government agencies and the Ministry of Public Health; nation-wide and local representative surveys were used to analyse body composition and leisure activities. Data on morbidity and mortality are from the Ministry of Public Health.

Results: The collapse of the European socialist countries and the Soviet Union, as well as the reinforced United States' blockade, provoked a sudden shortage of fuel, raw materials, imported foods and essential supplies. Per capita energy availability decreased, physical activity increased, and the prevalence of obesity decreased. Nutrition deficiencies were observed in the early 1990s, while the trend of morbidity from non-communicable disease continued to increase. The nutrition transition characteristics following the economic recovery in 1995-1996 resembled those of the 1980s because of the increased food availability, decreased physical activity and increased obesity prevalence.

Conclusions: Programmes to deal with the complex situation generated a response in a remarkably short time. Undesirable changes in diet composition and the reduction of physical activity constitute a challenge in the current post-critical stage that must be prevented.
\end{abstract}

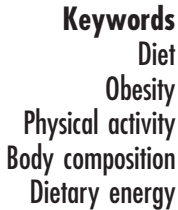

A major social and economic transformation began in Cuba in 1959, which has greatly impacted social and health indicators. The mortality rate for infants and children under five years of age, maternal mortality, and morbidity and mortality from communicable diseases were sharply reduced. At the same time, chronic non-communicable diseases (NCDs) related to lifestyles and diet patterns emerged as the leading causes of death ${ }^{1,2}$.

Unfavourable changes interrupted the normal pace of the country's economic development. Starting in 1989-90, the collapse of the European socialist countries and the Soviet Union abruptly reduced Cuban foreign trade by $80 \%$, leading to a sudden shortage of fuel, raw materials, imported foods and most essential supplies ${ }^{1,2}$. Consequently, food availability dropped and physical activity increased $^{1}$. Cuban access to international markets was drastically reduced, worsened by the well-known, longlasting US economic blockade. In spite of these conditions, the public health budget increased from 5.3\% to $7.8 \%$ of the gross national product (GNP), while per capita funds allocated for health services grew 34\% from 1990 to $1999^{1,2}$.

This paper describes changes in the basic components of the nutrition transition - diet, physical activity and body composition - as well as their impact on morbidity and mortality trends in the Cuban population in the nineties.

\section{Study methods}

Data on the country's economic situation, the Cuban public health policy, budget and statistics were obtained from La Salud Pública en Cuba. Hechos y Cifras ${ }^{2}$. The information on diet is from the Oficina Nacional de Estadísticas (ONE) and the Instituto de Nutrición e Higiene de los Alimentos. Per capita availability of energy and nutrients was obtained from the national food balance sheets. Information on body composition and nutritional status is from studies conducted in Havana in 1982, 1993 and 1998 by the Department of Growth and Development, 'Julio Trigo' Faculty of Medical Science, University of Havana. Body mass index (BMI) cut-off points $\left(\mathrm{kg} \mathrm{m}^{-2}\right)$ for adults were $<18.5$ (chronic energy deficiency), 18.524.99 (normal), 25-29.99 (overweight) and $\geq 30$ (obese). Information on physical activity (labour and leisure-time) is from the Primera Encuesta Nacional sobre Factores de Riesgo y Actividades Preventivas para Enfermedades Crónicas no Transmisibles, conducted by the Instituto de Higiene, Epidemiología y Microbiología (INHEM) and 


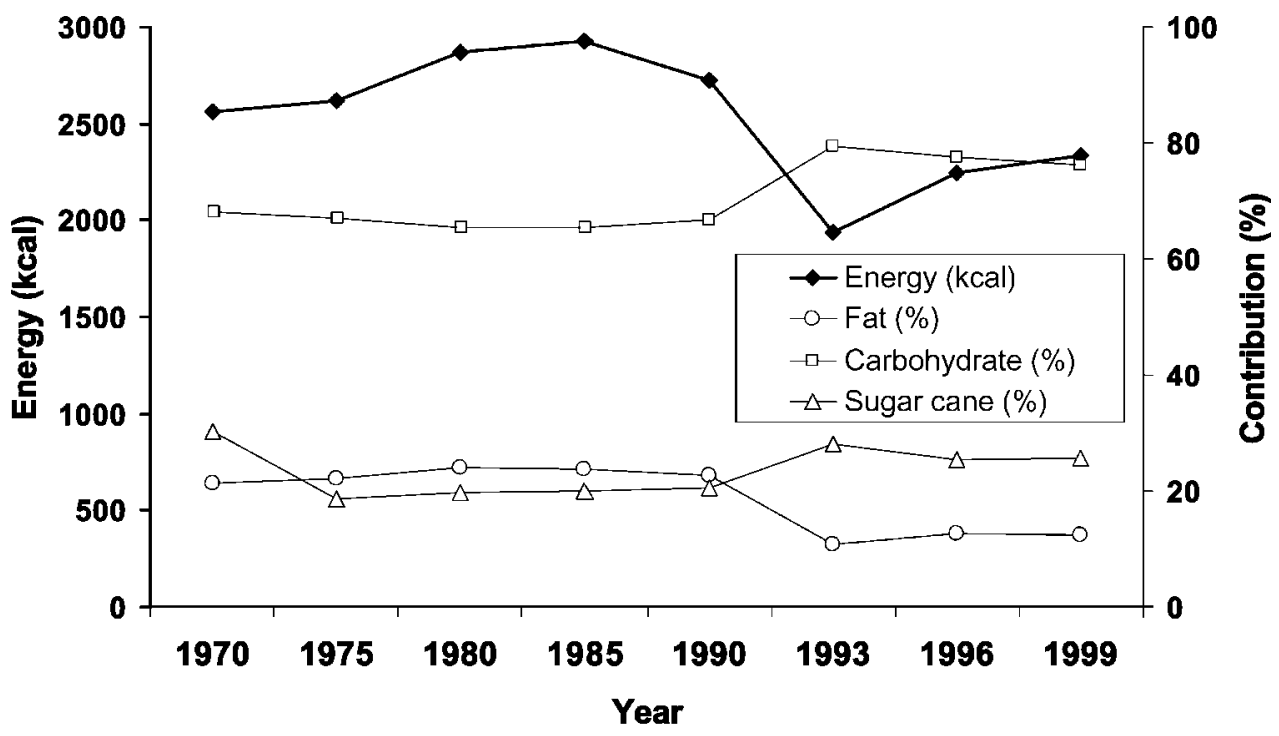

Fig. 1 Total dietary energy and percentage of energy from carbohydrate, fat and sugar; 1970 to 1999

ONE. Data on morbidity and mortality were obtained from the National Statistics Department of the Ministry of Public Health (NSD/PH) annual reports. Information on mortality from malignant tumours was obtained from the National Cancer Registry. Mortality rates were age-standardised with reference to the 1981 Cuban population.

Mortality causes were grouped according to the International Classification of Diseases and Related Health Problems, ninth revision, 1978.

\section{Shifts in diet structure and composition}

Before 1989, rising trends in food availability guaranteed full satisfaction of the population's energy and protein requirements $^{3}$. Data from food consumption surveys undertaken between 1980 and 1989 indicated that the contribution to energy intake was 11 to $15 \%$ from protein, 40 to $58 \%$ from carbohydrate (sugar cane, 19\%) and 27 to $48 \%$ from fat, while daily per capita energy intake rose from $2552 \mathrm{kcal}$ in 1965 to $2899 \mathrm{kcal}$ in $1988^{1,3}$. After 1989 , the process was reversed and reached its lowest level in 1993, when per capita availability of energy declined to $1940 \mathrm{kcal}$ (Fig. 1), a reduction of $32 \%$ in four years ${ }^{1,3,4}$. The sharp decrease in food imports, as well as an impaired food production within Cuba, contributed to this result ${ }^{1,3,4}$. In this setting, the qualitative and quantitative composition of Cuban diets changed. Commonly consumed foods disappeared from the market and were replaced by some unusual alternatives that did not correspond to traditional and cultural patterns.

The percentage of dietary fat in the energy intake decreased, while the contribution of carbohydrates (polished rice and refined cereals) increased from 64\% in 1990 to $79.4 \%$ in 1993. Availability of essential dietary amino acids and fatty acids declined as a consequence of a reduced availability of animal protein and edible oils and $\mathrm{fat}^{1,4}$. Sugar cane, a traditional source of energy in the Cuban diet, rose to $28 \%$ of total energy intake, almost three times that of the fat contribution (Fig. 1).

In 1996, shortly after economic recovery, energy availability (2335 kcal) was $15.8 \%$ higher than in 1993 ; in the same period, there was an increase of $19.6 \%$ in fat contribution to energy. In addition, the per capita availability of vegetables, which in 1999 reached the largest yield in 30 years (223.8 $\mathrm{g}_{\text {person }}{ }^{-1} \mathrm{day}^{-1}$ ), was 2.2 times higher compared with 1993 (102.7 $\mathrm{g} \mathrm{person}^{-1}$ day $^{-1}$ ). After 1996, carbohydrates (including sugar cane) decreased as a source of energy (Fig. 1), although still supplying a rather high percentage (ONE).

\section{Changes in body composition and nutritional status}

The body composition of adults and pre-school children was studied in Havana in 1982. In 20- to 64-year-old adults, overweight and obesity prevalence reached $31.3 \%$ and $13.3 \%$ in females $(n=3848)$ and $35.3 \%$ and $7.0 \%$ in males $(n=1985)$, respectively (Fig. 2$)^{5}$. In pre-school children $(n=1782)$, prevalence of moderate and severe overweight* reached $10 \%$ and $4.9 \%$, respectively. Obesity prevalences from a comparable study $(n=2372)$ in 1972 were $6.0 \%$ and $4.2 \%$ for pre-school children ${ }^{6}$.

In a sample of adult women $(n=3079)$ and men $(n=916)$ measured in the same province in 1993, the prevalence of overweight and obesity decreased by $41 \%$ and $53 \%$ in women and by $52.4 \%$ and $61 \%$ in men, respectively (Fig. 2) (Berdasco, personal communication). Therefore, the percentage of individuals with normal BMI $\left(18.5-24.99 \mathrm{~kg} \mathrm{~m}^{-2}\right.$ ) increased after 1982. The percentage

*Moderate overweight greater than two standard deviations ( $>2 \mathrm{SD}$ ) and severe overweight $>3$ SD of the World Health Organization (WHO) international reference values. 


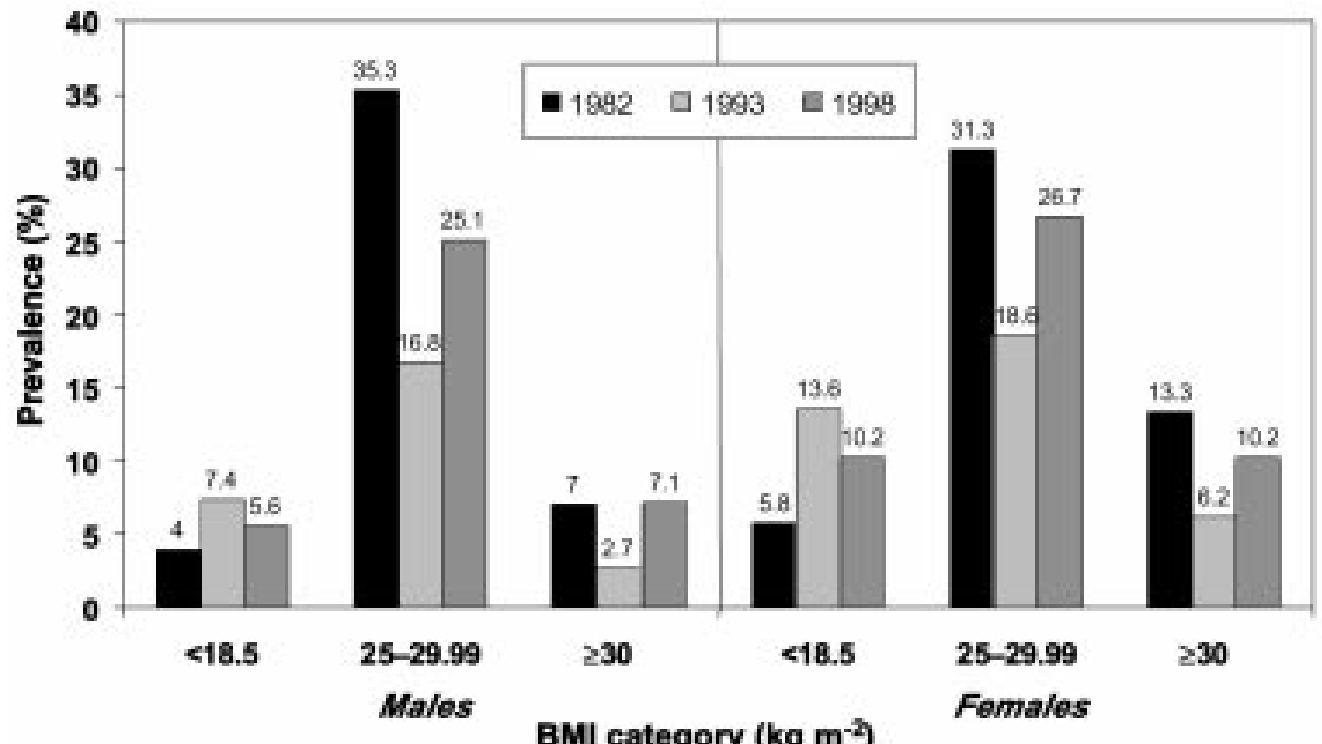

Fig. 2 Prevalence of chronic energy deficiency, overweight and obesity according to body mass index categories, by sex; adult Havana population (20 to 60 years of age), 1982, 1993 and 1998

of moderate and severe overweight pre-school children decreased to $4.2 \%$ and $1.0 \%$. However, the prevalence of weight-for-height below $-2 \mathrm{SD}$ of the WHO reference values shifted from $1.3 \%$ in 1972 , to $3.1 \%$ in 1982 , and to $0.4 \%$ in $1993^{6}$.

Evidence of a relapse in the population's body weight was shown in an adult population study conducted in Havana in 1998 (females, $n=3618$; males, $n=579$ ). Prevalences of overweight and obesity were higher than in 1993: in females $43 \%$ and $64 \%$, and in males $49 \%$ and $161 \%$, respectively (Fig. 2) (Berdasco, personal communication). The percentage of the population under 19 years of age, who were over the 90th percentile of the weight-forheight national reference values, shifted from $15.4 \%$ in $1972(n=7910)$ to $9.3 \%$ in $1993(n=4352)$; in 1998 $(n=4316)$, this figure rose to $13.1 \%$ (Esquivel, personal communication).

\section{Patterns of physical activity}

Adult physical activity was assessed in a multi-centre Pan American Health Organization (PAHO) research conducted in Havana in $1987^{7}$; $62 \%$ of men and $78 \%$ of women were classified as sedentary according to additional physical activity.* However, during the 1990s, bicycle riding and walking became the most important means of transportation in everyday labour and leisure activities ${ }^{3}$.

A 1995 national survey assessed physical activity in adults according to three criteria: main activity intensity ${ }^{8}$, additional activity ${ }^{9}$ and a combination of both; the

*Physical exercise less than twice per week and less than 15 minutes each time. sedentary population was estimated as $33 \%(25.7 \%$ in males and $39.8 \%$ in females). The increase in additional activities - bicycle riding ( $47.1 \%$ in men, $17.4 \%$ in women) and walking (22.0\% in men, $26.1 \%$ in women) - was the most significant finding. The study report emphasised the sustained increase of physical activity from 1991 to 1995 (INHEM, ONE).

The percentage of men and women working in industry or agriculture decreased from $20.4 \%$ and $12.6 \%$ to $16.8 \%$ and $11.4 \%$, respectively, from 1990 to 1999; the percentage working on less intensive activities increased from $66.5 \%$ to $70.9 \%$ (ONE).

\section{Morbidity and mortality trends}

High blood pressure (HBP) prevalence in the whole population increased from 49 to 128.2 per 1000, 2.6 times higher in 10 years, with women showing the highest rates. In the 60-64 year age group, rates increased from 187 to 655 per 1000, 3.5 times higher in the same period. Diabetes mellitus (DM) prevalence rates increased 1.3 times in the whole population, from 16.5 to 21.5 per 1000 , with the highest rates being observed in women and the 60-64 year age group $(70.4 \text { to } 122 \text { per 1000) })^{1,2,10}$. The incidences of lung, breast, prostate and stomach cancer have been nearly constant, while the incidences of colon and rectum cancer have increased in both men and women.

The main causes of death have been the same in the last 20 years. Cardiovascular disease (CVD) mortality has decreased slightly in the last 10 years, mainly due to a decrease in ischaemic heart disease mortality. DM and cerebrovascular disease trends have shown a slight 


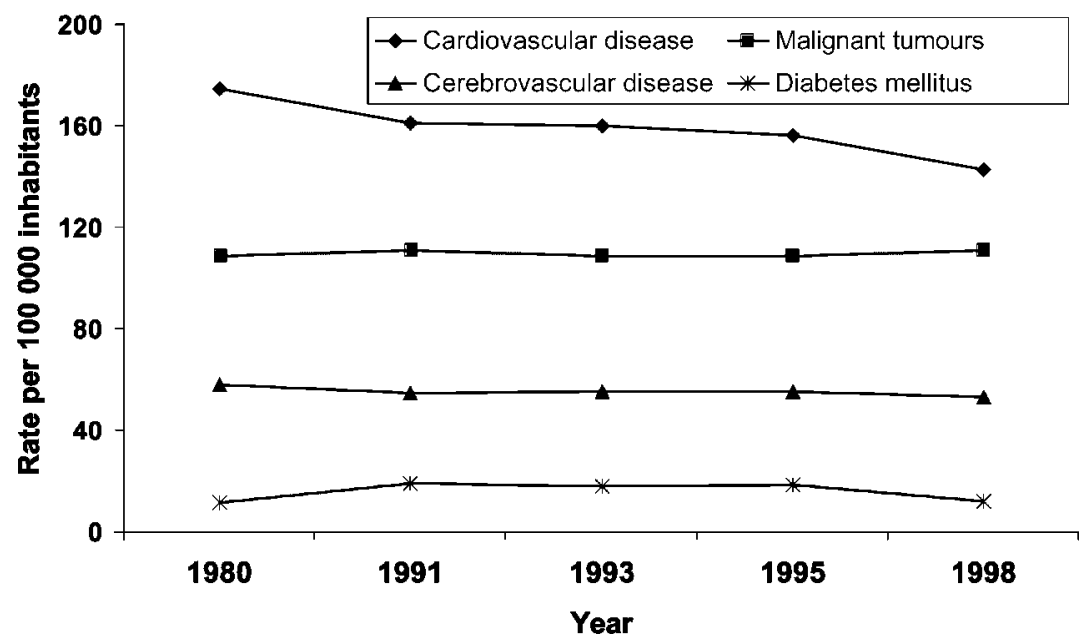

Fig. 3 Main causes of death for all ages in Cuba; 1980, 1991, 1993, 1995 and 1998, standardised rates per 100000 inhabitants

reduction while mortality rates from malignant tumours

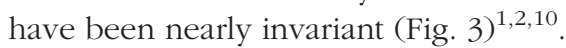

A 1993 survey conducted in Havana and Pinar del Rio indicated that $20 \%$ of children aged $1-5$ years and $35 \%$ of women of childbearing age were anaemic. Vitamin A marginal deficiency was reported in pre-school children (3.8\%), school children (4.9\%) and adolescents (4.3\%); and thiamine deficiency, assessed from erythrocyte transketolase levels, was observed in $25.5 \%$ of adolescents and $18.4 \%$ of adults 20 to 59 years. The percentage of low birth weight children increased from $7.3 \%$ in 1989 to $9 \%$ in $1993^{4,11,12}$.

\section{Discussion}

The nutrition transition in Cuba has evolved in three stages. The first one - since the early 1960s - was characterised by: (1) a diet gradually richer in fat, meat and sweeteners and poorer in carbohydrates and fibre; and (2) a decline in labour-intensive activities, resulting in an increasing number of obese people ${ }^{1,13}$. This pattern of transition is typical of low-income countries ${ }^{14}$. The leading causes of morbidity and mortality also shifted from infectious diseases and malnutrition to chronic and degenerative diseases ${ }^{1,2,13}$; Omram described the process in Cuba as a 'delayed model' transition ${ }^{15}$.

The collapse of the Eastern Europe socialist countries brought about a second stage - characterised by dramatic changes in diet, levels of physical activity and body composition - as a consequence of the severe economic crisis that affected the country from $1989-1990^{2}$. The extraordinary decrease in the per capita food availability had a large impact on the population's nutritional status. Nutrition deficiencies included increases in the percentage of anaemic pregnant women at the first trimester, anaemia and deficiency of marginal vitamins in children and adults, as well as an epidemic of optical neuropathy (EN), affecting nearly 50000 people between 1992 and
$1993^{1,4,11,12,16,17}$. Associated increases of non-labour physical activity contributed to reduced overweight and obesity prevalence; hence, the number of individuals with normal BMI in all age groups increased.

The shifts in diet and physical activity described above affected a large proportion of the population. A significant and positive impact on mortality trends was observed, but not in morbidity as could have been expected, in a more active and less overweight and obese population. The rising trends in HBP and DM morbidity of the 1980s remained in the 1990 s.

The active screening for NCDs supported by the 'Family Doctor' programme on a nation-wide scale could account for this. On the other hand, the emphasis on health promotion and disease prevention might need more time to show its impact on morbidity.

Several programmes were launched nation-wide to cope with this situation. Among the more relevant are the extension of the 'Maternal Homes' to every municipality, intended to guarantee better care of pregnant women; promotion of the 'Friend of the Mother and Child' health institution; the promotion of exclusive breast-feeding during the first four months of life; and free distribution of vitamin and mineral supplements to the whole Cuban population during the EN. A particularly relevant initiative has been the conception and sustainable development of urban agriculture, producing a large impact on food availability for urban populations.

The beginning of the current, post-critical stage became more evident in 1996, when the annual GNP rate increased $7.8 \%$, reflecting a recovery of the economy ${ }^{2}$. The factors explaining shifts in diet and physical activity during the previous stage have retained their trend. The current increase in per capita food availability and reduction in physical activity (basically non-labour activities) also resemble the first stage (i.e. more people are overweight, obese and less physically active); this is a warning signal for further action. 
Presently, there is no uniform way of marketing food as there was before the $1990 \mathrm{~s}^{1}$; alternatives include local production of rice, tubers, vegetables and livestock, among others, in small farms and co-operatives, and the household production of some foods (e.g. pork and lard; lard is cheaper than edible oil). Fast food restaurants, snacks and street food vendors selling 'junk' foods are now more frequent as well. On the other hand, the increasing availability of vegetables and fruits is an alternative that may favour a healthy diet. Therefore, in the current context, nutrition education programmes for the whole population must emphasise their promotion of a healthy diet and lifestyle to prevent NCD. This is one part of the programme 'Propositos, Objetivos y Metas para mejorar la salud de la población Cubana para el año 2010'.

The Cuban population faced a challenge in the last decade. The unexpected collapse of the Eastern European countries and the Soviet Union, as well as the reinforced US blockade, provoked the reduction in food availability, the increase in physical activity and fewer obese people. The vigorous and well-structured national programme to deal with the crisis generated a coherent response in a remarkably short time; such experiences could be a lesson for the international community. Moreover, the undesirable changes in diet composition and reduction in physical activity levels resemble the characteristics of the first nutrition transition stage and constitute a challenge in the current post-critical stage that must be prevented.

\section{Acknowledgements}

The authors thank Ana M Clua and the staff of the Department of Statistics in the Ministry of Public Health, Magaly Perez in the National Statistics Office and Susana Valdes in the National Cancer Registry. We also thank Dr Pablo Diez and Dr Mariano Bonet in the Institute of Hygiene, Epidemiology and Microbiology for their contributions on physical activity. Finally, we are deeply grateful to Dr Jorge Bacallao for his assistance in the revision of the manuscript.

\section{References}

1 Porrata C, Rodríguez-Ojea A, Jiménez S. The epidemiologic transition in Cuba. In: Peña M, Bacallao J, eds. Obesity and Poverty. A New Public Health Challenge. Scientific
Publication No. 576. Washington, DC: Pan American Health Organization (PAHO), 2000; 51-65.

2 Ministerio de Salud Pública (MINSAP), Dirección Nacional de Estadísticas. La Salud Pública en Cuba. Hechos y Cifras. Havana: MINSAP, 1999.

3 Porrata C, Súarez A, Hernández M, Jiménez S, Argüelles J, Cabrera A, et al. Dieta y salud en Cuba. Arch. Latinoam. Nutr. 1995; 45(Suppl. 1): 214S-9S.

4 Jiménez S, Porrata C, Rodríguez-Ojea A. Estudios alimentario nutricionales en relación con la neuropatía epidémica. In: Rojas F, ed. Neuropatía Epidémica en Cuba, 1992-1994. Havana: Ciencias Médicas, 1995; 159-68.

5 Berdasco A. Body mass index values in the Cuban adult population. Eur. J. Clin. Nutr. 1994; 48(Suppl. 3): S155-64.

6 Esquivel M, Romero J, Berdasco A, Gutiérrez M, Jiménez J, Posada E, et al. Estado nutricional de prescolares de Ciudad de La Habana entre 1972 y 1993. Rev. Panam. Salud. Publica 1997; 1(5): 349-54.

7 Organizacíon Panamerica de la Salud (OPS). Las Condiciones de Salud en las Américas. Scientific Publication No. 524. Washington, DC: OPS, 1990; 107.

8 WHO/FAO/UNU. Report: Energy and Protein Requirements. WHO Technical Report Series No. 724. Geneva: World Health Organization (WHO), 1985.

9 Physical Activity and Health [a report of the Surgeon General], US Department of Health and Human Services, 1996; Experts release new recommendation to fight America's epidemic of physical inactivity [news release], American College of Sports Medicine, 29 July 1993.

10 Ministerio de Salud Pública (MINSAP), Dirección Nacional de Estadísticas. Anuario Estadístico de Salud. Havana: MINSAP, 1999.

11 Macías C, Rodriguez-Ojea A, Chi N, Jiménez S, Zulueta D, Bates C. Biochemical evidence of thiamin depletion during the Cuban neuropathy epidemic, 1992-1993. Am. J. Clin. Nutr. 1996; 64: 347-53.

12 Zulueta D, Gay J, Rodriguez-Ojea A, Jiménez S, Terry B, Macías $\mathrm{C}$, et al. Evaluación de deficiencias nutricionales mediante sitios centinela. Rev. Esp. Nutr. Comunit. 1997; 3-4: 122-6.

13 Amador M, Peña M. Nutrition and health issues in Cuba: strategies for a developing country. Food Nutr. Bull. 1991; 4 : 311-7.

14 Popkin B. The nutrition transition and its health implications in lower-income countries. Public Health Nutr. 1998; 1(1): $5-21$.

15 Omram AR. The epidemiologic transition: a theory of the epidemiology of population change. Milbank Q. 1971; 49: 509-38.

16 Gay J, Porrata C, Hernández M, Clúa A, Argüelles J, Cabrera A, et al. Factores dietéticos de la neuropatía epidémica en la Isla de la Juventud, Cuba. Bol. Oficina Sanit. Panam. 1994; 117: 389-98.

17 Roman G. Epidemic neuropathy: a plea to end the United States' economic embargo on a humanitarian basis. Neurology 1994; 44: 1784-6. 